\title{
Pulmonary vascular resistance predicts early mortality in patients with diffuse fibrotic lung disease and suspected pulmonary hypertension
}

\author{
T J Corte, ${ }^{1,2}$ S J Wort, ${ }^{1}$ M A Gatzoulis, ${ }^{1}$ P Macdonald, ${ }^{2}$ D M Hansell, ${ }^{1}$ A U Wells ${ }^{1}$
}

- Additional methods are published online only at http:// thorax.bmj.com/content/vol64/ issue 10

${ }^{1}$ Royal Brompton Hospital and National Heart and Lung Institute, London, UK;

${ }^{2}$ University of New South

Wales, Sydney, Australia

Correspondence to:

Dr A U Wells, Interstitial Lung Disease Unit, Royal Brompton Hospital and National Hearth and Lung Institute, Imperial College, Emmanuel Kaye Building, 1B Manresa Road, London SW3 6LP, UK: athol.wells@rbht.nhs.uk

Received 21 December 2008 Accepted 2 June 2009 Published Online First 21 June 2009

\begin{abstract}
Background: Pulmonary hypertension $(\mathrm{PH})$ is associated with a poor prognosis in diffuse lung disease (DLD). A study was undertaken to compare the prognostic significance of invasive and non-invasive parameters in patients with DLD and suspected PH.
\end{abstract}

Methods: Hospital records of consecutive patients with DLD undergoing right heart catheterisation $(\mathrm{RHC})$ were reviewed $(n=66)$. Mean pulmonary artery pressure (mPAP), pulmonary vascular resistance (PVR) and noninvasive variables were examined against early (within 12 months) and overall mortality. A priori thresholds were examined against early mortality. Relationships between mPAP, PVR and non-invasive markers were assessed.

Results: Fifty patients had PH on RHC (mean (SD) mPAP 33.5 (11.8) mm Hg, PVR 5.9 (4.3) Wood units (WU)). Raised PVR was strongly associated with early mortality (odds ratio (OR) 1.30; 95\% confidence interval (CI) 1.11 to $1.52 ; p=0.001)$, with PVR $\geqslant 6.23$ WU being the optimal threshold after adjustment for age, gender, composite physiological index (CPI) and diagnosis of idiopathic pulmonary fibrosis (OR 11.09; $95 \% \mathrm{Cl} 2.54$ to 48.36 ; $p=0.001)$. Early mortality was linked, albeit less strongly, to right ventricular dilation at echocardiography, but not to other non-invasive variables or mPAP. Overall mortality was most strongly associated with increasing CPI levels. Correlations between PVR and non-invasive variables were moderate $\left(R^{2}<0.32\right)$, improving little following construction of a multivariate index which did not itself predict mortality.

Conclusion: In severe DLD, early mortality is strongly linked to increased PVR but not to other RHC or noninvasive variables. These findings suggest that the threshold for RHC in severe DLD should be low, enabling prioritisation of aggressive treatment including lung transplantation.

In end-stage diffuse lung disease, prognosis is generally poor. Physicians require reliable prognostic markers for early death to refine the triage of patients for aggressive treatments and transplantation referral. On this basis, it has been recommended by an expert group that pulmonary hypertension $(\mathrm{PH})$ is an indication for immediate listing for lung transplantation for interstitial lung disease at large. ${ }^{1} \mathrm{PH}$ is not uncommon in diffuse lung disease and is a malignant prognostic determinant, as shown in studies of idiopathic pulmonary fibrosis $(\mathrm{IPF})^{2-8}$ and advanced pulmonary sarcoidosis. ${ }^{9}$

In most studies, $\mathrm{PH}$ is quantified using the mean or systolic pulmonary artery pressure rather than pulmonary vascular resistance (PVR), and the systolic pulmonary artery pressure (sPAP) is a component of the Northern American Lung Allocation Score. ${ }^{10}$ The prognostic value of PVR has not been quantified in diffuse lung disease. However, in a recent study of patients with a variety of chronic lung diseases awaiting lung transplantation, raised PVR was strongly predictive of short-term mortality whereas a number of other variables, including mean pulmonary artery pressure (mPAP), were not. ${ }^{11}$

In the current study we have compared PVR, mPAP and other variables as predictors of early mortality in patients with severe diffuse lung disease. A second goal of this study was to determine whether the prognostic role of right heart catheterisation (RHC) could be replicated by non-invasive surrogate markers. RHC is regarded as the reference standard in the evaluation of $\mathrm{PH}$ but is moderately invasive and resource-limited. We therefore studied the prognostic value of a noninvasive composite index modelled against measured PVR.

\section{METHODS \\ Subjects}

A retrospective review of consecutive patients with diffuse fibrotic lung disease undergoing RHC between February 1987 and April 2007 ( $n=66$ ) was undertaken. RHC was performed in cases of suspected $\mathrm{PH}$ based on clinical criteria or as part of a pretransplantation assessment. Clinical criteria for RHC included echocardiographic right ventricular systolic pressure (RVSP) $>40 \mathrm{~mm} \mathrm{Hg}$ or right ventricular (RV) dilation and dyspnoea or hypoxaemia not explained by the underlying fibrosis. Multidisciplinary diagnoses were made using current guidelines for idiopathic interstitial pneumonia, ${ }^{12}$ with retrospective reclassification (integrating biopsy data, high resolution computed tomography (HRCT) findings and observed longitudinal behaviour) in patients diagnosed before 2002. Twenty-two patients were also included in a radiology study addressing a separate hypothesis. ${ }^{13}$ Follow-up to death or to 1 June 2008 was complete in 62 of the 66 cases.

\section{Measurements}

Right heart catheterisation (RHC)

RHC measurements were performed at rest using standard techniques (Swan-Ganz catheters, Edwards Life Sciences, Irvine, California, USA). Cardiac output (CO) was calculated by the Fick equation: $\mathrm{CO}=$ (oxygen consumption)/(arterial oxygen saturation mixed venous oxygen saturation) using standardised 
reference tables to estimate oxygen consumption. ${ }^{13}$ PVR was calculated using the formula: PVR $=(\mathrm{mPAP}-\mathrm{mLAP}) / \mathrm{CO},{ }^{14}$ where $\mathrm{mLAP}=$ mean left atrial pressure. Left ventricular end diastolic pressure was used to estimate mLAP in patients with simultaneous left heart catheterisation $(n=51)$. Pulmonary capillary wedge pressure $(n=30)$ was used to estimate mLAP in the remaining 15 cases.

\section{Non-invasive investigations}

All patients had pulmonary function testing and two-dimensional echocardiography. Forty-two patients underwent the six minute walk test $(6 \mathrm{MWT})$. If patients had multiple tests, the test closest to the date of RHC was used. Full details of the echocardiography, pulmonary function and 6MWT methodology are available in the online supplement.

\section{Rationale for a priori thresholds}

A priori thresholds examined against early death using logistic regression included:

- RHC thresholds

- mPAP: 17, 25, 35 and 40 mm Hg; ${ }^{3} 6$

- PVR: 3, 3.56 and 6.23 Wood units (WU). ${ }^{11}{ }^{15}$

- Non-invasive thresholds

- RVSP: 30, 35, 40 and 50 mm Hg; ${ }^{2}$ 16-18

- Transfer factor for carbon monoxide (TLCO): 30\%, 35\% and $40 \%$ predicted $;^{19-22}$

- Forced vital capacity (FVC): 50\% and 60\% predicted; ${ }^{23}$

- Arterial oxygen tension $\left(\mathrm{PaO}_{2}\right): 7,7.5$ and $8 \mathrm{kPa} .^{24}$

The rationale for $\mathrm{mPAP}$ thresholds was based on IPF studies in which mPAP of 17 and $25 \mathrm{~mm} \mathrm{Hg}$ denoted poorer outcomes. $^{3426}$ Threshold mPAP values of 35 and $40 \mathrm{~mm} \mathrm{Hg}$ were included as measures of moderate and severe $\mathrm{PH} .{ }^{6}$ For PVR, current guidelines recommend $\geqslant 3$ WU for the identification of pulmonary arterial hypertension (PAH) ${ }^{15}$ a threshold associated with a poorer prognosis in transplant candidates. ${ }^{11}$ Using linear regression, PVR values equivalent to $\mathrm{mPAP}$ of 25 and $35 \mathrm{~mm} \mathrm{Hg}$ were calculated as 3.56 and $6.23 \mathrm{WU}$, and these threshold values were evaluated. The rationale for the remaining a priori thresholds is provided in the online supplement.

\section{Statistical analysis}

All analyses were performed using STATA statistical software Version 10.0 (Stata Corp, College Station, Texas, USA). Data are expressed as mean and standard deviation (SD) or median (range), as appropriate. Group comparisons were made using the Student $t$ test or Wilcoxon rank-sum test. Outcome was evaluated for overall mortality (Cox regression, with satisfaction of the assumptions of proportional hazards analysis) and death within the first year (logistic regression): covariates included PVR, mPAP, RVSP, right atrial (RA) and RV dilation, TLCO, FVC, composite physiological index (CPI), $\mathrm{PaO}_{2}, 6 \mathrm{MWT}$ desaturation $\leqslant 88 \%$, diagnosis of IPF and male gender.

Univariate relationships were examined using Pearson or Spearman rank correlation tests as appropriate. Using stepwise analysis, a model was constructed to fit non-invasive variables to PVR. Covariates consisted of the CPI (included to adjust for the severity of interstitial lung disease) and the four variables found to be significantly linked to PVR on univariate analysis. The assumptions of multiple linear regression were satisfied, as judged by testing for heteroscedasticity and omitted variables. The prognostic value of this model was evaluated against overall mortality and against death in the first year. Analysis was repeated for the subgroup $(n=52)$ of patients with mLAP below $15 \mathrm{~mm} \mathrm{Hg}$ and for individual diagnostic subgroups.

\section{RESULTS}

\section{Baseline parameters}

The baseline characteristics of the 66 patients (mean (SD) mPAP $33.6(11.8) \mathrm{mm} \mathrm{Hg}$, PVR 5.9 (4.3) WU) are summarised in table 1. Fifty patients $(76 \%)$ had $\mathrm{PH}(\geqslant 25 \mathrm{~mm} \mathrm{Hg})$ and 28 (42\%) had moderate to severe $\mathrm{PH}(\geqslant 35 \mathrm{~mm} \mathrm{Hg}$ ) on RHC and nine $(14 \%)$ had significant coronary artery disease. Fifty $(76 \%)$ had one or more echocardiographic findings compatible with $\mathrm{PH}$ (raised RVSP, $\mathrm{n}=40$; RA dilation, $\mathrm{n}=24$; RV dilation, $\mathrm{n}=30$; $\mathrm{RV}$ dysfunction, $\mathrm{n}=23)$. Thirty-seven of the 66 patients $(56 \%)$ had a TLCO $\leqslant 30 \%$ and 33 of 42 (79\%) had significant oxygen desaturation on $6 \mathrm{MWT}$ to $\leqslant 88 \%$.

\section{Early mortality}

During the study period there were 31 deaths, including 17 deaths within 12 months of RHC. As shown in table 2, patients dying within 12 months of RHC had significantly higher PVR $(\mathrm{p}<0.001)$ and mPAP $(\mathrm{p}=0.03)$ and lower pulmonary acceleration time (PAT) $(p=0.007)$. Age, gender, pulmonary function, RVSP and 6MWT desaturation did not differ between survivors and patients dying within 1 year.

Logistic regression for death within 1 year showed that PVR $\geqslant 6.23$ WU was strongly linked to early mortality with an eightfold increase in death within the first year (odds Ratio (OR) 8.15; 95\% confidence interval (95\% CI) 2.38 to 27.87; $\mathrm{p}=0.001)$. This finding remained robust following adjustment for age, gender, CPI and IPF diagnosis (OR 11.09; 95\% CI 2.54 to 48.36; $p=0.001 ;$ table 3 ). These findings remained highly significant with the exclusion of each diagnostic subgroup (table 3 ). These trends remained strong for patients with mLAP $<15 \mathrm{~mm} \mathrm{Hg}$ ( $\mathrm{n}=52 ;$ OR 12.11; 95\% CI 2.12 to 69.10; $\mathrm{p}=0.005$ ) but not for patients with mLAP $\geqslant 15 \mathrm{~mm} \mathrm{Hg}$ $(\mathrm{n}=14)$. Coronary artery disease was not linked to mortality or to raised left heart pressures. No mPAP or mean RAP threshold was predictive of early death.

On echocardiography, the presence of RV dilation was associated with a fourfold risk of early death $(p=0.02)$ whereas no RVSP threshold was helpful in the prediction of early death. No TLCO, FVC, CPI or $\mathrm{PaO}_{2}$ threshold was associated with early death. The diagnosis of IPF was only marginally associated with early death $(p=0.07)$.

\section{Overall mortality}

PVR was the strongest haemodynamic predictor of mortality (table 4, fig 1). Raised PVR was associated with higher mortality (hazards ratio (HR) 1.13; 95\% CI 1.05 to $1.22 ; p=0.001$ ), remaining significant after adjustment for age, gender and disease severity (CPI). Mean PAP and CO were not predictive of overall mortality.

On echocardiography, RV dilation was associated with marginally higher mortality. One, two and three-year survival rates for those with RV dilation were $63.3 \%, 46.4 \%$ and $36.6 \%$ compared with $85.9 \%, 69.8 \%$ and $45.5 \%$ for those without RV dilation. Other echocardiographic parameters, including RVSP, were not significantly linked to outcome. Pulmonary function impairment (TLCO $\%, \mathrm{FVC} \%, \mathrm{PaO}_{2}$ and CPI) was associated with higher mortality. CPI was strongly associated with higher mortality (HR 1.07, 95\% CI 1.03 to $1.10, \mathrm{p}<0.001$ ), remaining significant after adjustment for age, gender and PVR. No deaths occurred in patients without 6MWT desaturation. 
Table 1 Demographic and clinical data of the study population $(\mathrm{n}=66)$

\begin{tabular}{|c|c|}
\hline Parameters & No \\
\hline \multicolumn{2}{|l|}{ Clinical parameters* } \\
\hline Age (years) & $57(12)$ \\
\hline Gender (F:M) & $28: 38$ \\
\hline Smoking (pack years) & $\begin{array}{l}27 \text { non-smokers, } 31 \text { ex- } \\
\text { smokers, } 7 \text { current smokers, } \\
1 \text { unknown }\end{array}$ \\
\hline Time from presentation (months) & $33(4-264)$ \\
\hline WHO class & $3(1-4)$ \\
\hline $\begin{array}{l}\text { Working diagnosis (based on } \\
\text { multidisciplinary consensus } \\
\text { including lung biopsy when } \\
\text { available) }\end{array}$ & $\begin{array}{l}\text { IPF }(n=16) \\
\text { Idiopathic NSIP }(n=6) \\
\text { CTD-related fibrosis }(n=17) \\
\text { Sarcoidosis }(n=12) \\
\text { Other interstitial diseases } \\
(n=15)\end{array}$ \\
\hline Biopsy diagnosis & $n=13(20 \%)$ \\
\hline \multicolumn{2}{|l|}{ Right heart catheter* } \\
\hline mPAP $(\mathrm{mm} \mathrm{Hg})$ & $33.6(11.8)$ \\
\hline mRAP (mm Hg) & $5.9(4.2)$ \\
\hline $\mathrm{mLAP}(\mathrm{mm} \mathrm{Hg}) \dagger$ & $10.7(5.1)$ \\
\hline PVR (Wood units) & $5.9(4.3)$ \\
\hline PVR index (Wood units/m²) & $10.4(7.1)$ \\
\hline Cardiac output (I/min) & $4.3(1.2)$ \\
\hline Cardiac index $\left(1 / \mathrm{min} / \mathrm{m}^{2}\right)$ & $2.3(0.5)$ \\
\hline \multicolumn{2}{|l|}{ Echocardiography } \\
\hline $\operatorname{RVSP}(\mathrm{mm} \mathrm{Hg}, \mathrm{n}=48)$ & $56(24-102)$ \\
\hline PAT $(m s, n=46)$ & $100(33-144)$ \\
\hline \multicolumn{2}{|l|}{ Pulmonary function } \\
\hline TLCo \% $(n=65)$ & $29.6(14.7)$ \\
\hline $\mathrm{Kco} \%(\mathrm{n}=65)$ & $52.0(19.7)$ \\
\hline TLC \% $(n=61)$ & $72.5(20.2)$ \\
\hline $\mathrm{FEV}_{1} \%(\mathrm{n}=62)$ & $62.4(23.3)$ \\
\hline FVC \% $(n=62)$ & $67.9(23.1)$ \\
\hline $\mathrm{PaO}_{2}(\mathrm{kPa}, \mathrm{n}=61)$ & $8.4(2.2)$ \\
\hline $\mathrm{Paco}_{2}(\mathrm{kPa}, \mathrm{n}=61)$ & $5.0(0.9)$ \\
\hline $\mathrm{CPI}(\mathrm{n}=62)$ & $56.9(14.6)$ \\
\hline \multicolumn{2}{|l|}{$6 \mathrm{MWT}(\mathrm{n}=42)$} \\
\hline End $\mathrm{SpO}_{2}(\%)$ & $81.4(8.4)$ \\
\hline 6MWT distance $(\mathrm{m})$ & $254.6(128.1)$ \\
\hline
\end{tabular}

*Data expressed as mean (SD) or median (range). $n=66$ unless otherwise specified.

$\dagger$ Pulmonary capillary wedge pressure used to calculate PVR in the absence of left ventricular end diastolic pressure $(n=15)$. $\mathrm{CPI}$, composite physiological index; CTD, connective tissue disease; $\mathrm{FEV}_{1}$, forced expiratory volume in $1 \mathrm{~s}$; FVC, forced vital capacity; $\mathrm{IPF}$, idiopathic pulmonary fibrosis; Kco, transfer factor corrected for alveolar volume; $\mathrm{mLAP}$, mean left atrial pressure; mPAP, mean pulmonary artery pressure; mRAP, mean right atrial pressure; 6MWT, six minute walk test; NSIP, non-specific interstitial pneumonia; $\mathrm{PaCO}_{2}$, arterial carbon dioxide tension; $\mathrm{PaO}_{2}$, arterial oxygen tension; PAT, pulmonary acceleration time; PVR, pulmonary vascular resistance; RVSP, right ventricular systolic pressure; $\mathrm{SpO}_{2}$, oxygen saturation on pulse oximetry; TLC, total lung capacity; TLCO, transfer factor for carbon monoxide; WHO, World Health Organization.

\section{Non-invasive estimates of mPAP and PVR}

Table 5 summarises the relationship between invasive (mPAP and PVR) and non-invasive variables as judged by nonparametric correlation. Significant but weak correlations were present between echocardiographic markers (RVSP and PAT) and both PVR and mPAP. An RVSP of $\geqslant 40 \mathrm{~mm} \mathrm{Hg}$ correctly identified $79.2 \%$ of patients with PH on RHC (sensitivity $91.7 \%$; specificity $41.7 \%$; area under the curve $0.77,95 \%$ CI 0.62 to 0.92 ). The specificity of RVSP improved (58.3\%) with a higher RVSP threshold ( $\geqslant 50 \mathrm{~mm} \mathrm{Hg}$ ).
Table 2 Comparison of patients dying within 12 months with those surviving at 12 months

\begin{tabular}{lccc}
\hline & $\begin{array}{c}\text { Death within } \\
\text { 12 months }\end{array}$ & $\begin{array}{c}\text { Survival at } \\
\text { 12 months }\end{array}$ & p Value* \\
\hline mPAP (mm Hg) & $39.0(14.1)$ & $31.7(10.4)$ & 0.03 \\
PVR (WU) & $9.4(5.8)$ & $4.6(2.8)$ & $<0.001$ \\
PVR index (WU/m²) & $16.4(9.7)$ & $8.5(4.8)$ & $<0.001$ \\
mLAP (mm Hg) & $12.2(6.4)$ & $9.5(5.0)$ & 0.11 \\
Cardiac output (I/min) & $3.8(1.3)$ & $4.4(1.1)$ & 0.06 \\
PAT (ms) & $69.4(21.2)$ & $99.5(28.1)$ & 0.005 \\
$\mathrm{PaO}_{2}(\mathrm{kPa})$ & $7.4(1.4)$ & $8.8(2.3)$ & 0.03
\end{tabular}

Values are mean (SD).

${ }^{*}$ Student $t$ test.

mLAP, mean left atrial pressure; mPAP, mean pulmonary artery pressure; $\mathrm{PaO}_{2}$, arterial oxygen tension; PAT, pulmonary acceleration time; PVR, pulmonary vascular resistance; WU, Wood units.

Stepwise linear regression revealed that $\mathrm{PaO}_{2}(p=0.02 ; 95 \%$ CI -1.40 to -0.16 ) and RVSP ( $p=0.002 ; 95 \%$ CI 0.03 to 0.14 ) were independent determinants of PVR when adjusted for disease severity as determined by CPI (following correction for the five covariates assessed). The following equation predicted PVR with an equation $r^{2}$ of 0.37 :

Predicted PVR $=12.6+0.09 \times \mathrm{RVSP}-0.78 \times \mathrm{PaO}_{2}-0.09 \times$ CPI

However, predicted PVR values were not linked to overall mortality $(p=0.51)$ and were only of borderline significance for the prediction of death within the first 12 months $(p=0.06)$.

\section{DISCUSSION}

In diffuse lung disease, optimal therapeutic triage including prioritisation of transplantation requires accurate prognostic evaluation. We report for the first time that PVR provides discriminatory prognostic information not provided by mPAP levels or non-invasive evaluation. PVR was the strongest haemodynamic predictor for early mortality, independent of the severity of pulmonary fibrosis, as judged by CPI levels. We report an eightfold increase in early mortality above an a priori PVR threshold of $6.23 \mathrm{WU}$. Importantly, this finding was independent of the diagnosis of IPF, which was itself only marginally predictive of early mortality.

Lung biopsy provides invaluable prognostic guidance in less severe disease. However, in advanced disease, biopsy is often impracticable and less prognostically useful. In one study, survival did not differ between biopsy-proven IPF and nonspecific interstitial pneumonia (NSIP) in severe disease. ${ }^{27}$ Patients with severe hypersensitivity pneumonitis have an outcome similar to that of IPF. ${ }^{28}$ In the current study, early mortality was not linked to diagnosis. It therefore appears that, in end-stage disease, the usefulness of diagnostic subclassification diminishes, justifying the amalgamation of diagnostic categories in transplantation studies of patients with diffuse lung disease. ${ }^{1129-33}$ This consideration prompted us to evaluate determinants of early mortality in a mixed population with severe disease referred for RHC.

Our findings provide indirect support for the hypothesis that, in severe fibrotic lung disease, the severity of pulmonary vascular insufficiency rather than the severity of pulmonary fibrosis or a diagnosis of IPF or connective tissue disease determines short-term mortality. However, the selection bias inherent in the decision to perform RHC needs to be stressed. Throughout the study period RHC was performed in suspected or clinically overt $\mathrm{PH}$ rather than in consecutive unselected patients with severe pulmonary fibrosis. RHC was performed 
Table 3 Predictors of early mortality (death within 12 months of right heart catheterisation): mortality as determined by logistic regression for continuous parameters and a priori threshold values

\begin{tabular}{|c|c|c|}
\hline & OR $(95 \% \mathrm{Cl})$ & p Value \\
\hline \multicolumn{3}{|l|}{ Right heart catheterisation } \\
\hline PVR (continuous; WU) & $1.30(1.11$ to 1.52$)$ & $0.001 * \dagger$ \\
\hline$P V R \geqslant 3$ & $3.00(0.61$ to 14.86$)$ & 0.18 \\
\hline$P V R \geqslant 3.56$ & 2.71 (0.68 to 10.72$)$ & 0.16 \\
\hline$P V R \geqslant 6.23$ & 8.15 (2.38 to 27.87$)$ & $0.001 * \dagger$ \\
\hline mPAP (continuous; mm Hg) & $1.05(1.00$ to 1.01$)$ & 0.03 \\
\hline$m P A P \geqslant 17$ & $1.82(0.20$ to 16.78$)$ & 0.60 \\
\hline$m P A P \geqslant 25$ & $3.00(0.61$ to 14.86$)$ & 0.18 \\
\hline $\mathrm{mPAP} \geqslant 35$ & $1.78(0.58$ to 5.40$)$ & 0.31 \\
\hline$m P A P \geqslant 45$ & $3.91(1.05$ to 14.50$)$ & 0.04 \\
\hline mRAP (continuous; mmHg) & $0.97(0.84$ to 1.11$)$ & 0.65 \\
\hline $\mathrm{mLAP}$ & 0.93 (0.84 to 1.04$)$ & 0.19 \\
\hline Cardiac output (I/min) & $0.59(0.33$ to 1.03$)$ & 0.06 \\
\hline \multicolumn{3}{|l|}{ Echocardiography } \\
\hline RVSP $(\mathrm{mm} \mathrm{Hg})$ : & $1.02(0.99$ to 1.06$)$ & 0.23 \\
\hline RA dilation & 2.55 (0.82 to 7.89$)$ & 0.10 \\
\hline RV dilation & $4.13(1.25$ to 13.64$)$ & $0.02^{*}$ \\
\hline Echocardiographic evidence of PH§ & $3.00(0.61$ to 14.86$)$ & 0.18 \\
\hline \multicolumn{3}{|l|}{ Pulmonary function } \\
\hline TLCo \% predicted: & $0.96(0.92$ to 1.01$)$ & 0.12 \\
\hline FVC $\%$ predicted $\$$ & $0.99(0.97$ to 1.02$)$ & 0.58 \\
\hline $\mathrm{CPI}$ & $1.03(0.99$ to 1.08$)$ & 0.14 \\
\hline $\mathrm{PaO}_{2}(\mathrm{kPa}) \mathrm{F}$ & $0.71(0.51$ to 0.98$)$ & 0.04 \\
\hline \multicolumn{3}{|l|}{ Clinical } \\
\hline Age & $1.00(0.95$ to 1.04$)$ & 0.93 \\
\hline Male gender & 1.07 (0.35 to 3 to 28$)$ & 0.90 \\
\hline Time from presentation (months) & $1.01(1.00$ to 1.02$)$ & 0.05 \\
\hline Coronary artery disease & $1.94(0.40$ to 9.49$)$ & 0.42 \\
\hline WHO class & 2.67 (1.21 to 5.88$)$ & $0.02^{*}$ \\
\hline Exclusion of IPF patients & 8.04 (1.72 to 37.59$)$ & 0.008 \\
\hline $\begin{array}{l}\text { Exclusion of CTD-related fibrosis } \\
\text { patients }\end{array}$ & $9.92(2.30$ to 42.85$)$ & 0.002 \\
\hline Exclusion of idiopathic NSIP patients & $9.9(2.68$ to 36.53$)$ & 0.001 \\
\hline Exclusion of sarcoidosis patients & 8.89 (2.34 to 33.81$)$ & 0.001 \\
\hline
\end{tabular}

${ }^{*}$ Remains significant following adjustment for age, gender, $\mathrm{CPI}$ and diagnosis of IPF (PVR: OR 1.41, 95\% Cl 1.17 to $1.71, \mathrm{p}<0.001$; PVR $\geqslant 6.23$ : OR $11.09,95 \% \mathrm{Cl} 2.54$ to 48.36, $\mathrm{p}=0.001$; RV dilatation: $\mathrm{OR} 6.19,95 \% \mathrm{Cl} 1.47$ to $26.02, p=0.01$; WHO class: OR $2.63,95 \% \mathrm{Cl} 1.03$ to $6.68, \mathrm{p}=0.04$ ).

$\uparrow$ Themains significant for patients with $\mathrm{mLAP}<15 \mathrm{~mm} \mathrm{Hg}$ (PVR: OR $1.25,95 \% \mathrm{Cl} 1.06$ to $1.47, p=0.007$; PVR $\geqslant 6.23$ : OR $6.5,95 \% \mathrm{Cl} 1.71$ to $24.68, p=0.006$ ).

$\$$ No a priori threshold value significantly predicted early mortality.

§Patients with RVSP $\geqslant 40 \mathrm{~mm} \mathrm{Hg}$ or right atrial or right ventricular dilation or right ventricular dysfunction.

$\mathrm{Cl}$, confidence interval; $\mathrm{CPI}$, composite physiological index; CTD, connective tissue disease; FVC, forced vital capacity; IPF, idiopathic pulmonary fibrosis; $\mathrm{mLAP}$, mean left atrial pressure; $\mathrm{mPAP}$, mean pulmonary artery pressure; mRAP, mean right atrial pressure; NSIP, non-specific interstitial pneumonia; $\mathrm{OR}$, odds ratio; $\mathrm{PaO}_{2}$, arterial oxygen tension; $\mathrm{PH}$, pulmonary arterial hypertension; PVR, pulmonary vascular resistance; RA, right atrial; RV, right ventricular; RVSP, right ventricular systolic pressure; TLCO, transfer factor for carbon monoxide; WHO, World Health Organization; WU, Wood units.

when clinically indicated at various stages of the disease process (median 3 years from presentation). Confirmation of the prognostic importance of pulmonary vasculopathy in an unselected group would require a large prospective study or a more accurate non-invasive marker of pulmonary vascular insufficiency such as serum brain natriuretic peptide, which is linked to outcome in idiopathic $\mathrm{PAH}$ and chronic respiratory disease $^{34}$ but has yet to be evaluated prospectively.

Our findings differ from those in IPF in which $\mathrm{mPAP}^{3}{ }^{4}$ and RVSP $^{2} 5$ are linked to mortality. There are at least two possible explanations for this apparent discrepancy. First, patients with severe disease were the focus of our study, with average TLCO
Table 4 Predictors of overall survival (mortality as determined by Cox's proportional hazards regression)

\begin{tabular}{lll}
\hline & HR (95\% CI) & p Value \\
\hline $\begin{array}{ll}\text { Right heart catheterisation } \\
\text { PVR }\end{array}$ & $1.13(1.05$ to 1.22$)$ & $0.001^{*}$ \\
PVR index & $1.07(1.03$ to 1.12$)$ & $0.003^{*}$ \\
mPAP & $1.02(0.99$ to 1.05$)$ & 0.25 \\
mRAP & $0.96(0.87$ to 1.05$)$ & 0.32 \\
mLAP & $0.94(0.88$ to 1.00$)$ & 0.05 \\
Cardiac output & $0.86(0.63$ to 1.18$)$ & 0.34 \\
Cardiac index & $0.69(0.36$ to 1.33$)$ & 0.27 \\
Echocardiography & & \\
RV dilation & $1.92(0.93$ to 3.98$)$ & 0.08 \\
RV dysfunction & $1.72(0.84$ to 3.53$)$ & 0.14 \\
RVSP & $1.00(0.98$ to 1.02$)$ & 0.81 \\
Pulmonary function & & \\
TLco \% & $0.94(0.91$ to 0.98$)$ & 0.001 \\
Kco \% & $0.98(0.96$ to 0.99$)$ & 0.03 \\
FVC \% & $0.98(0.96$ to 0.99$)$ & 0.02 \\
Composite physiological index & $1.06(1.03$ to 1.10$)$ & $<0.0001 \dagger$ \\
Pa0 ${ }_{2}$ & $0.73(0.60$ to 0.89$)$ & 0.002 \\
Clinical & & \\
Male gender & & 0.06 \\
Age & $2.10(0.96$ to 4.57$)$ & 0.47 \\
IPF diagnosis & $1.01(0.98$ to 1.04$)$ & 0.001 \\
WHO class & $3.33(1.58$ to 7.00$)$ & 0.006 \\
\hline
\end{tabular}

${ }^{*}$ Significant following adjustment for age, gender and CPI (PVR: HR 1.13, 95\% $\mathrm{Cl} 1.03$ to $1.23, p=0.009$; PVR index: HR $1.24,95 \%$ Cl 1.11 to $1.38 ; p<0.001)$.

†Significant following adjustment for age, gender and PVR (CPI: HR 1.06, 95\% Cl 1.03 to $1.10, p=0.001$ )

$\mathrm{Cl}$, confidence interval; $\mathrm{FVC}$, forced vital capacity; HR, hazards ratio; IPF, idiopathic pulmonary fibrosis; Kco, transfer factor corrected for alveolar volume; $\mathrm{mLAP}$, mean left atrial pressure; mPAP, mean pulmonary artery pressure; mRAP, mean right atrial pressure; $\mathrm{PaO}_{2}$, arterial oxygen tension; PVR, pulmonary vascular resistance; $\mathrm{RV}$, right ventricular; RVSP, right ventricular systolic pressure; TLCo, transfer factor for carbon monoxide; WHO, World Health Organization.

levels less than $30 \%$. In end-stage disease, pulmonary pressures may fall as the right ventricle fails, confounding relationships between pulmonary pressures and mortality reported in IPF populations of lesser average disease severity. ${ }^{3-5}$ Second, the link between pulmonary pressures and mortality may vary with the

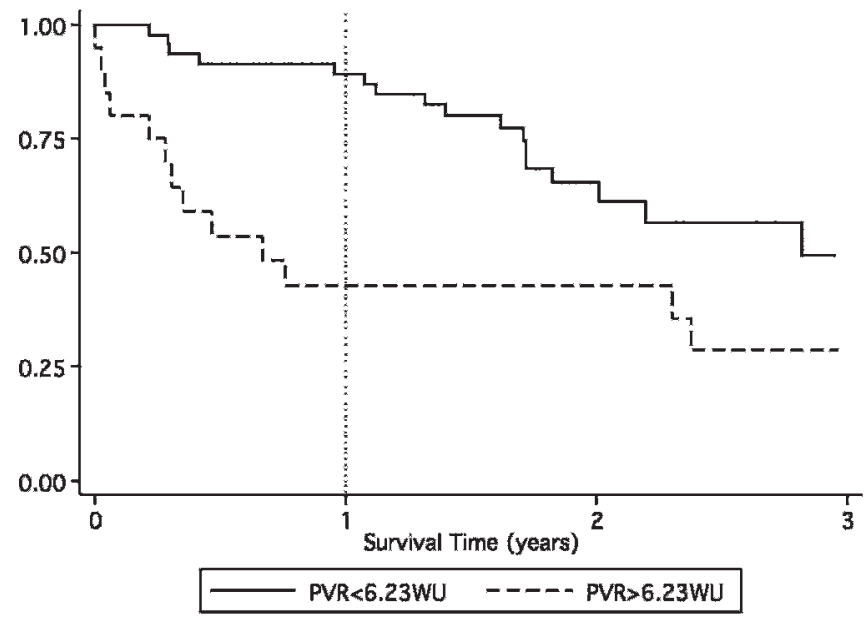

Figure 1 Kaplan-Meier curves for survival for pulmonary vascular resistance (PVR). The PVR threshold of 6.23 Wood units (WU) delineated patients in terms of survival. Patients with PVR $\geqslant 6.23$ WU had poorer overall survival, with the major difference being attributable to the difference seen in the first 12 months. 
Table 5 Correlation of right heart catheter measures (PVR and mPAP) with non-invasive clinical parameters

\begin{tabular}{|c|c|c|c|c|}
\hline & \multicolumn{2}{|l|}{ mPAP } & \multicolumn{2}{|l|}{ PVR } \\
\hline & $\mathbf{R}^{*}$ & p Value & $\mathbf{R}^{*}$ & p Value \\
\hline WHO class $(n=66)$ & 0.23 & 0.06 & 0.25 & 0.04 \\
\hline \multicolumn{5}{|l|}{ Echocardiography } \\
\hline $\operatorname{RVSP}(n=48)$ & 0.56 & $<0.001$ & 0.52 & $<0.001$ \\
\hline РАТ $(n=46)$ & -0.39 & 0.008 & -0.49 & $<0.001$ \\
\hline \multicolumn{5}{|l|}{ Pulmonary function } \\
\hline TLC \% $(n=61)$ & 0.30 & 0.02 & 0.21 & 0.11 \\
\hline TLCO \% (n=65) & -0.01 & 0.88 & -0.12 & $0.33 \dagger$ \\
\hline Kco \% (n=65) & -0.26 & 0.04 & -0.31 & 0.01 \\
\hline FVC $\%(n=62)$ & 0.12 & 0.34 & 0.16 & 0.21 \\
\hline $\mathrm{PaO}_{2}(\mathrm{n}=61)$ & -0.27 & 0.03 & -0.23 & 0.08 \\
\hline $\mathrm{PacO}_{2}(\mathrm{n}=61)$ & -0.05 & 0.71 & -0.02 & $0.91 \dagger$ \\
\hline CPI $(n=62)$ & -0.03 & 0.83 & 0.02 & 0.86 \\
\hline \multicolumn{5}{|l|}{$6 \mathrm{MWT}(\mathrm{n}=42)$} \\
\hline $6 \mathrm{MWT}$ end-test $\mathrm{SpO}_{2}$ & -0.03 & 0.86 & -0.03 & 0.87 \\
\hline 6MWT distance & -0.02 & 0.92 & -0.11 & 0.48 \\
\hline
\end{tabular}

${ }^{*}$ Pearson or $†$ Spearman correlation coefficient $(\mathrm{R})$ as appropriate.

$\mathrm{CPI}$, composite physiological index; $\mathrm{FEV}_{1}$, forced expiratory volume in $1 \mathrm{~s}$; FVC, forced vital capacity; Kco, transfer factor corrected for alveolar volume; mPAP, mean pulmonary artery pressure; $6 \mathrm{MWT}$, six minute walk test; $\mathrm{PaCO}_{2}$, arterial carbon dioxide tension; $\mathrm{PaO}_{2}$, arterial oxygen tension; PAT, pulmonary acceleration time; PVR, pulmonary vascular resistance; RVSP, right ventricular systolic pressure; $\mathrm{SpO}_{2}$, oxygen saturation on pulse oximetry; TLC, total lung capacity; TLCo, transfer factor for carbon monoxide; WHO, World Health Authority.

rapidity of disease progression to end-stage disease and may therefore be stronger in IPF. Thus, our findings are applicable to patients with advanced disease but not to the full spectrum of disease severity in individual disorders.

The strikingly increased early mortality in patients with PVR $\geqslant 6.23 \mathrm{WU}$ is consistent with a recent study in end-stage lung disease in which increased PVR independently predicted pretransplant mortality in a variety of chronic lung diseases. ${ }^{11}$ In addition, in idiopathic PAH, PVR may be a better prognostic marker than pulmonary artery pressure.$^{35}{ }^{36}$ As discussed above, mPAP may fall (relative to PVR) preterminally as the right ventricle fails. Indeed, in the current study there were five patients with increased PVR and normal mPAP. PVR is coupled to both pulmonary pressures and cardiac output, ${ }^{37}$ is a marker of the peripheral vasculature and may better reflect the pathophysiology of $\mathrm{PH}$ in fibrotic lung disease in which vascular ablation, chronic hypoxic vasoconstriction and vascular remodelling are seen histologically in peripheral vessels. ${ }^{38}$ Additionally, main pulmonary artery size on HRCT scanning does not correlate with pulmonary arterial pressures in interstitial lung disease, ${ }^{39}{ }^{40}$ supporting the hypothesis that interstitial disease may be associated with a more aggressive vascular phenotype (whether due to fibrotic ablation or to the vasculopathic effect of cytokines generated in fibrotic lung tissue).

Our findings have direct relevance to the prioritisation of patients for lung transplantation. Since 2005 a transplant allocation score has been used in North America. ${ }^{10}$ PVR may be an important additional factor for consideration in this transplant allocation algorithm, which currently takes into account systolic PAP ${ }^{10}$ which our findings suggest has little value in predicting short-term prognosis.

The prognostic significance of RV dilation on echocardiography mirrors findings in idiopathic $\mathrm{PAH} .{ }^{41}$ As RV dilation reflects uncoupling of the right ventricle-often a late findingit is predictable that RV dilation is linked to early mortality. Our data suggest that RV dilation is a better prognostic indicator than RVSP alone. RV dilation is readily identifiable at echocardiography and may be an important marker in future outcome studies.
The relationship between baseline disease severity and overall mortality is not confined to studies of single disorders, as shown in studies of IPF and fibrotic NSIP. ${ }^{27}{ }^{42}$ We demonstrate the prognostic importance of the CPI in advanced fibrotic lung disease across histological diagnoses. However, no pulmonary function parameter was predictive of early death. This suggests that early death is associated with $\mathrm{PH}$ rather than the severity of the underlying fibrotic lung disease. This is consistent with a study of patients with IPF assessed for transplantation in whom the presence of $\mathrm{PH}$, but not lower pulmonary function, was associated with poorer outcomes at 1, 2 and 3 years. ${ }^{4}$

No single non-invasive measurement correlated well with PVR or mPAP on RHC. No $\mathrm{R}^{2}$ value was greater than 0.32 suggesting that, at best, only $30 \%$ of the variation in PVR was explained by these non-invasive variables. RVSP correlated best with $\mathrm{MPAP}$ and PVR. However, the sensitivity and specificity of RVSP for a diagnosis of $\mathrm{PH}$ on RHC was moderate, in keeping with previous studies highlighting the inadequacy of echocardiography in fibrotic lung disease. ${ }^{17}$ In our study, multiple linear regression was used to develop predictive equations for PVR using non-invasive measurements. PVR was independently determined by the combination of RVSP and $\mathrm{PaO}_{2}$. However, predicted values were not as accurate in predicting prognosis as their RHC counterparts. Zisman et al reported an externally validated model predicting mPAP based on pulmonary function and oxygen saturation..$^{44}$ Although a reliable non-invasive marker would be clinically useful, our results suggest that RHC remains an integral tool in diagnostic and prognostic assessment in selected patients with diffuse lung disease.

The limitations of a retrospective study design with respect to selection of patients for RHC are discussed above. Four other issues merit consideration. First, there was a risk of "chance fitting" due to the number of variables assessed, prompting us to examine candidate a priori thresholds identified in previous studies. Although PVR emerged as a striking prognostic marker, the possibility of chance fitting cannot be excluded. However, with adjustment for multiple comparisons (taking into account all 13 continuous variables), the association between PVR and early mortality remained significant $(p=0.01)$. In addition, this 
finding is plausible on pathophysiological grounds, as discussed earlier, and is consistent with studies in idiopathic PAH as well as in patients awaiting lung transplantation. ${ }^{11}$ Second, the wide confidence intervals for the prognostic value of PVR in our study should be acknowledged, underlining the need for further prospective evaluation. Third, our study cohort included 14 patients with raised left heart pressures. However, early death did not vary in prevalence with left heart pressures (data not shown), and the prognostic value of PVR was unchanged on exclusion of patients with raised left heart pressures. Moreover, the presence of coronary artery disease was not separately associated with early mortality and was therefore not a major confounding factor.

Oxygen desaturation below $88 \%$ at $6 \mathrm{MWT}$ has been reported as a malignant prognostic determinant in IPF and NSIP. ${ }^{45}{ }^{46}$ In our study, mortality was confined to patients with desaturation at $6 \mathrm{MWT}$ to $88 \%$ or lower. However, no significant difference was seen for early death for patients with and without 6MWT oxygen desaturation (data not shown). In our study, 6MWT data were available for 42 patients (64\%), including five who progressed to early death. The mean 6MWT distance was low at $254 \mathrm{~m}$, in keeping with the severity of their underlying disease. However, patients with more severe functional impairment were unable to perform the 6MWT or were tested on supplemental oxygen $(n=7)$, limiting further prognostic evaluation.

We conclude that, in severe diffuse lung disease, raised PVR strongly predicts death within 1 year independent of disease severity or diagnosis of IPF. PVR is superior to other measurements at RHC and also to non-invasive tests (alone or in combination). These findings suggest that, in advanced lung disease, prognostic information that is only obtainable by RHC has important management implications (including prioritisation and referral for lung transplantation).

Funding: This research has been partly supported by an educational grant from Actelion Pharmaceuticals.

Competing interests: None.

Provenance and peer review: Not commissioned; externally peer reviewed.

\section{REFERENCES}

1. Behr J, Ryu JH. Pulmonary hypertension in interstitial lung disease. Eur Respir J 2008;31:1357-67.

2. Nadrous HF, Pellikka PA, Krowka MJ, et al. The impact of pulmonary hypertension on survival in patients with idiopathic pulmonary fibrosis. Chest 2005;128(6 Suppl):616-7S.

3. Hamada K, Nagai S, Tanaka S, et al. Significance of pulmonary arterial pressure and diffusion capacity of the lung as prognosticator in patients with idiopathic pulmonary fibrosis. Chest 2007;131:650-6.

4. Lettieri CJ, Nathan SD, Barnett SD, et al. Prevalence and outcomes of pulmonary arterial hypertension in advanced idiopathic pulmonary fibrosis. Chest 2006;129:746-52.

5. Nadrous HF, Pellikka PA, Krowka MJ, et al. Pulmonary hypertension in patients with idiopathic pulmonary fibrosis. Chest 2005;128:2393-9.

6. Shorr AF, Wainright JL, Cors CS, et al. Pulmonary hypertension in patients with pulmonary fibrosis awaiting lung transplant. Eur Respir J 2007;30:715-21.

7. Agarwal R, Gupta D, Verma JS, et al. Noninvasive estimation of clinically asymptomatic pulmonary hypertension in idiopathic pulmonary fibrosis. Indian J Chest Dis Allied Sci 2005;47:267-71.

8. Nathan SD, Shlobin OA, Ahmad S, et al. Serial development of pulmonary hypertension in patients with idiopathic pulmonary fibrosis. Respiration 2008;76:288-94.

9. Shorr AF, Helman DL, Davies DB, et al. Pulmonary hypertension in advanced sarcoidosis: epidemiology and clinical characteristics. Eur Respir J 2005;25:783-8.

10. Egan TM, Murray S, Bustami RT, et al. Development of the new lung allocation system in the United States. Am J Transplant 2006;6(5 Pt 2):1212-27.

11. Selimovic N, Andersson B, Bergh CH, et al. Pulmonary hemodynamics as predictors of mortality in patients awaiting lung transplantation. Transplant Int 2008;21:314-9.

12. American Thoracic Society/European Respiratory Society. Idiopathic pulmonary fibrosis: diagnosis and treatment; international consensus statement. Am J Respir Crit Care Med 2000:161:646-64.

13. Cholley BP, Payen D. Noninvasive techniques for measurements of cardiac output. Curr Opin Crit Care 2005;11:424-9

14. Mazza E, Taichman D. Functions and control of the pulmonary circulation. In: Taichman D, Mandel J, eds. Pulmonary vascular disease. 1st ed. Philadelphia: Elsevier, 2006:1-19
15. Galie N, Torbicki A, Barst R, et al. Guidelines on diagnosis and treatment of pulmonary arterial hypertension. The Task Force on Diagnosis and Treatment of Pulmonary Arteria Hypertension of the European Society of Cardiology. Eur Heart J 2004;25:2243-78.

16. Nathan SD, Shlobin OA, Barnett SD, et al. Right ventricular systolic pressure by echocardiography as a predictor of pulmonary hypertension in idiopathic pulmonary fibrosis. Respir Med 2008;102:1305-10.

17. Arcasoy SM, Christie JD, Ferrari VA, et al. Echocardiographic assessment of pulmonary hypertension in patients with advanced lung disease. Am J Respir Crit Care Med 2003;167:735-40.

18. Rich S. Executive summary from the World Symposium on Primary Pulmonary Hypertension. Evian, France: co-sponsored by the World Health Organization, 1998

19. Raghu G, Brown KK, Bradford WZ, et al. A placebo-controlled trial of interferon gamma-1b in patients with idiopathic pulmonary fibrosis. $N$ Engl J Med 2004;350:125-33.

20. Nathan SD, Shlobin OA, Ahmad S, et al. Pulmonary hypertension and pulmonary function testing in idiopathic pulmonary fibrosis. Chest 2007;131:657-63.

21. Mogulkoc N, Brutsche MH, Bishop PW, et al. Pulmonary function in idiopathic pulmonary fibrosis and referral for lung transplantation. Am J Respir Crit Care Med 2001;164:103-8.

22. Jezek V, Fucik J, Michaljanic A, et al. The prognostic significance of functional tests in cryptogenic fibrosing alveolitis. Bull Eur Physiopathol Respir 1980;16:711-20.

23. Martinez FJ, Safrin S, Weycker D, et al. The clinical course of patients with idiopathic pulmonary fibrosis. Ann Intern Med 2005;142(12 Pt 1):963-7.

24. Domiciliary Oxygen Therapy Services. Clinical guidelines and advice for prescribers. A report of the Royal College of Physicians. London: Royal College of Physicians, 1999

25. Keller CA, Shepard JW Jr, Chun DS, et al. Pulmonary hypertension in chronic obstructive pulmonary disease. Multivariate analysis. Chest 1986;90:185-92.

26. Letsou GV, Franco KL, Kopf GS, et al. Heart-lung transplantation: initial experience in New England. Conn Med 1990;54:419-24.

27. Latsi PI, du Bois RM, Nicholson AG, et al. Fibrotic idiopathic interstitial pneumonia: the prognostic value of longitudinal functional trends. Am J Respir Crit Care Med 2003;168:531-7.

28. Perez-Padilla R, Salas J, Chapela R, et al. Mortality in Mexican patients with chronic pigeon breeder's lung compared with those with usual interstitial pneumonia. Am Rev Respir Dis 1993;148:49-53.

29. Feltrim MI, Rozanski A, Borges AC, et al. The quality of life of patients on the lung transplantation waiting list. Transplant Proc 2008;40:819-21.

30. Tuppin MP, Paratz JD, Chang AT, et al. Predictive utility of the 6-minute walk distance on survival in patients awaiting lung transplantation. J Heart Lung Transplant 2008;27:729-34.

31. Martinu T, Babyak MA, O'Connell CF, et al. Baseline 6-min walk distance predicts survival in lung transplant candidates. Am J Transplant 2008;8:1498-505.

32. Shitrit D, Gershman Y, Peled N, et al. Risk factors for death while awaiting lung transplantation in Israeli patients: 1997-2006. Eur J Cardiothorac Surg 2008;34:444-8.

33. Perez-Enguix D, Morales P, Tomas JM, et al. Computed tomographic screening of pulmonary arterial hypertension in candidates for lung transplantation. Transplant Proc 2007;39:2405-8.

34. Leuchte HH, Baumgartner RA, Nounou ME, et al. Brain natriuretic peptide is a prognostic parameter in chronic lung disease. Am J Respir Crit Care Med 2006:173:744-50.

35. Sitbon 0, Humbert $\mathrm{M}$, Nunes $\mathrm{H}$, et al. Long-term intravenous epoprostenol infusion in primary pulmonary hypertension: prognostic factors and survival. J Am Coll Cardiol 2002:40:780-8

36. Paciocco G, Martinez FJ, Bossone E, et al. Oxygen desaturation on the six-minute walk test and mortality in untreated primary pulmonary hypertension. Eur Respir $\mathrm{J}$ 2001;17:647-52.

37. Chemla D, Castelain V, Herve $\mathrm{P}$, et al. Haemodynamic evaluation of pulmonary hypertension. Eur Respir J 2002;20:1314-31.

38. Leach RM, Treacher DF. Clinical aspects of hypoxic pulmonary vasoconstriction. Exp Physiol 1995;80:865-75.

39. Zisman DA, Karlamangla AS, Ross DJ, et al. High-resolution chest computed tomography findings do not predict the presence of pulmonary hypertension in advanced idiopathic pulmonary fibrosis. Chest 2007;132:773-9.

40. Devaraj $\mathbf{A}$, Wells $A U$, Meister MG, et al. The effect of diffuse pulmonary fibrosis on the reliability of CT signs of pulmonary hypertension. Radiology 2008;249:1042-9.

41. van Wolferen SA, Marcus JT, Boonstra A, et al. Prognostic value of right ventricular mass, volume, and function in idiopathic pulmonary arterial hypertension. Eur Heart J 2007;28:1250-7.

42. Jegal Y, Kim DS, Shim TS, et al. Physiology is a stronger predictor of survival than pathology in fibrotic interstitial pneumonia. Am J Respir Crit Care Med 2005:171:639-44.

43. Zisman DA, Ross DJ, Belperio JA, et al. Prediction of pulmonary hypertension in idiopathic pulmonary fibrosis. Respir Med 2007;101:2153-9.

44. Zisman DA, Karlamangla AS, Kawut SM, et al. Validation of a method to screen for pulmonary hypertension in advanced idiopathic pulmonary fibrosis. Chest 2008;133:640-5

45. Flaherty KR, Andrei AC, Murray S, et al. Idiopathic pulmonary fibrosis: prognostic value of changes in physiology and six-minute-walk test. Am J Respir Crit Care Med 2006;174:803-9.

46. Lama VN, Flaherty KR, Toews GB, et al. Prognostic value of desaturation during a 6 minute walk test in idiopathic interstitial pneumonia. Am J Respir Crit Care Med 2003:168:1084-90. 